plants, birds (including migrants seen from cliff tops), mammals and other animals as well as, most comprehensively, areas of natural history interest. This means that there is plenty of detailed information but that the text is never unnecessarily cluttered up.

It is perhaps inevitable in a comprehensive book of this kind that there should be a few inaccuracies. Rough Tor is not the highest point in Cornwall; the red squirrel is no longer widespread in the county, though it manages to survive in small numbers in two or three western woods; no one is likely to be 'rewarded by the sight of a Montagu's Harrier' in winter; and I would not describe the collared dove as being 'introduced' to Britain. And there are indications that the author has not been too well served by his proof-reader, particularly in regard to the spelling of proper names. But these are relatively minor criticisms. No naturalist interested in Devon or Cornwall can afford to be without this invaluable book.

RENNIE BERE

\title{
Pesticides and Freshwater Fauna by R.C. Muirhead-Thomson. Academic Press, £3.50
}

Animal life in rivers, streams and lakes is affected by pesticides in two ways: from the intentional use of the chemical substances to control of undesirable aquatic fauna for public health reasons, such as the larvae of mosquitoes and blackfly, or the snails which carry the organisms causing bilharziasis; and also from accidental or incidental introduction of pesticides intended for some other purpose. Perhaps the best remembered example of the latter was when in the 1950 s blanket aerial spraying of high concentrations of DDT took place over extensive forest areas of the USA and Canada to control forest pests such as spruce budworm. The catastrophic effects on stream life first drew attention to the dangers of applying these powerful and persistent chemicals indiscriminately on such a vast scale.

Since then a considerable amount of research has been undertaken all over the world both into the value of modern pesticides in controlling organisms of medical importance and also into their role as dangerous contaminants of the freshwater environment. The present book is a valuable attempt to summarise the published results of this research, primarily to evaluate the methods and techniques which have been used to establish the facts rather than the facts and observations themselves. The author endorses the view that improved methods of detecting and identifying trace residues of these very powerful and persistent chemical substances have outrun our knowledge of their biological effects. Nevertheless, much interesting, and at times disturbing, information is given in chapters on Pesticides and Freshwater Fish, Chemical Control of Freshwater Snails in Public Health, Insects of Public Health Importance and Impact of Pesticides on Aquatic Invertebrates. In discussing the effects of the many new organophosphorous larvicides on aquatic invertebrates the author says, 'Our knowledge about the ecological impact of such recent compounds will continue to lag behind until such time as the problem is tackled in a much more systematic and coordinated manner'. Let us hope that biologists will take up the challenge at least as actively as their chemist colleagues have done, not merely in the restricted field of organophosphorus compounds but across the whole spectrum of pesticides that reach rivers, streams and lakes, before irreversible damage is done. 